\title{
Briefly about Nutrition
}

\author{
Siniša Franjić* \\ Faculty of Law, International University of Brcko District, Brcko, Bosnia and Herzegovina \\ *Corresponding Author: Siniša Franjić, Faculty of Law, International University of Brcko District, Brcko, Bosnia and Herzegovina.
}

Received: October 17, 2019; Published: November 05, 2019

DOI: $10.31080 /$ ASNH.2019.03.0530

\begin{abstract}
Our eating habits dictate how we feel and how our brains work. After eating three donuts for breakfast, we will feel lethargic and tired. But if we eat forest fruits, grains and nuts, we will feel dashinged and energized. A healthy or proper nutrition is provides the body an optimal intake of calories, vitamins, minerals and fluids, and an optimal ratio of proteins, carbohydrates and fats, to ensure the body's needs for building, energy and protective substances.

Keywords: Nutrition; Health; Diet
\end{abstract}

\section{Introduction}

Nutrition is the study of all of the interactions that occur between people and the food they eat [1]. It involves understanding which nutrients the human body needs, what kind of foods contain them, how the human body uses them, and the impact they have on human health. Nutrition also involves sociological, cultural, economic, and technological factors and the role they play in obtaining and choosing the foods we eat.

Humans don't eat individual nutrients; they eat food. Food provides the body with energy and nutrients; it also contains other substances, such as chemicals found in plants. These chemicals are called phytochemicals. Although they have not been defined as nutrients, they do have health-promoting properties.

When we eat the right combination of foods, our diet provides all of the nutrients and other substances we need to stay healthy. If we choose a poor combination of foods, we may be missing out on some nutrients and consuming others in excess.

There are more than 40 nutrients that are essential to human life. We need to consume these essential nutrients in our diets because our bodies either cannot make them or they cannot make them in large enough amounts for optimal health. Different foods contain different nutrients in varying amounts and combinations. For example, beef, chicken, and fish provide protein, vitamin B6, and iron; bread, rice, and pastas provide carbohydrate, folic acid, and niacin; fruits and vegetables provide carbohydrate, fiber, vita$\min \mathrm{A}$, and vitamin $\mathrm{C}$; and vegetable oils provide fat and vitamin $\mathrm{E}$. In addition to the nutrients that they naturally contain, many foods have nutrients added to them by fortification to replace losses that occur during cooking and processing or to supplement the diet. Dietary supplements are also a source of nutrients. Although most people can meet their nutrient needs without them, supplements can be useful for maintaining health and preventing deficiencies.
The dividing line between food science and food technology is often blurred because food technology uses and exploits the knowledge of food science [2]. The link between food science and technology is well illustrated in solving the foremost problem of feeding the world's rapidly increasing population. The problems inherent in deciding what foods meet the nutritional needs of people, the nutritional content of various foods, how to preseve and serve food with minimum nutritional loss, these form part of food science. But to use this information, it must be applied-foods must be grown, stored. processed, preserved and transported on a large scale and this is the area of food technology.

Food science embraces many sciences but a chemical approach to the subject is a natural and important one. Firstly, food materials are composed entirely of chemical compounds. Secondly, nearly all manufactured foods have "additives", which are chemical compounds. These may be added to improve colour, flavour, texture or other desirable qualities. Further, the changes that occur in food when it is processed, cooked, eaten and used by the body are chemical changes.

The science of human nutrition deals with all the effects on people of any component found in food [3]. This starts with the physiological and biochemical processes involved in nourishment-how substances in food provide energy or are converted into body tissues, and the diseases that result from insufficiency or excess of essential nutrients (malnutrition). The role of food components in the development of chronic degenerative disease like coronary heart disease, cancers, dental caries, etc., are major targets of research activity nowadays. The scope of nutrition extends to any effect of food on human function: fetal health and development, resistance to infection, mental function and athletic performance. There is growing interaction between nutritional science and molecular biology which may help to explain the action of food compo- 
nents at the cellular level and the diversity of human biochemical responses.

All living things on this planet require nourishment to fuel and support vital operations [4]. For instance, plants get water, minerals and nitrogen from the soil and produce their own carbohydrate, protein, and fat. Meanwhile, animals consume other forms of life, such as plants and animals or their products, in order to survive. For humans, we consume animals and their products (for example, milk, eggs) and/or plants and their products (fruits, vegetables, cereal grains). Even eating some forms of microbes (or microorganisms) such as yeast and some bacteria can help us survive and promote vitality. Humans exist at the upper end of the food chain, meaning that a large variety of life-forms are food to us, but we are not regular food for other life-forms. Plants, on the other hand, maintain a position at the other end of the food chain as they are food for many life-forms, including insects, fish, and mammals.

\section{Energy}

All the energy needed for growth and repair of the body, for muscular activity of all kinds and for all the work done by cells comes from the metabolism of carbohydrate, fat, protein and alcohol [5]. The numerous other items of the diet, even though essential for other reasons, do not provide energy, although many are directly involved in the chemical reactions which yield energy. If the diet is adequate and properly balanced the energy normally comes chiefly from carbohydrate and fat, while most of the protein is used for cell growth and repair. When there is not enough carbohydrate and fat, the protein is used for energy and is then not available for other purposes. As dietary protein is generally less abundant than carbohydrate and fat, and usually more expensive, using protein for energy is comparatively wasteful. In some communities, however, there may be plentiful protein and it may then be eaten in sufficient quantity to be used for both cell building and for energy.

The intake of food is governed in health by the appetite which under ordinary conditions controls the weight of the body with remarkable precision. Many people taking only moderate care are able to keep their weight more or less unchanged over several decades. If they take food in excess by only a small amount, that excess energy can be disposed of as heat and thereby prevent fat accumulation. This seems to work very efficiently in some people. It is, however, easy to override the natural controlling mechanism and consume substantially more energy than is required. When this happens the excess energy is stored in the body as fat.

Energy balance is the difference between energy intake, which can be metabolised, and total energy expenditure [6]. It could be said that the human body's energy state is balanced when its energy expenditure is equal to its energy intake.
The human body requires energy to perform its many functions, to facilitate muscle activity and developmental demands and to correct problems that may have been caused by disease or injury. Energy needs are met by the energy obtained from the body's diet, which derives from foods either of plant or of animal origin. Food energy is released in the body through the oxidation of carbohydrates, fats, proteins (which are called macronutrients) and alcohol.

If energy intake and expenditure are not equal, the result will be either a positive energy balance, in which body energy stores (and mainly fat) are increased, or a negative energy balance, in which the body falls back on using its energy stores (fat, protein and glycogen). Consequently, the body's energy balance (along with other factors) determines to a large extent its weight and general health status.

According to the definition given by the World Health Organization (WHO), energy requirement is 'the level of energy intake that will balance energy expenditure when we have a body size and composition, and a level of physical activity consistent with longterm good health'. Energy requirements are influenced by various factors, such as the developmental stage we are in (e.g. children's or adolescents' requirements are different from those of the adults), body size, the amount and intensity of physical activity (athletes and manual workers, for instance, obviously require more energy than people doing clerical work or leading sedentary lives), gender, illness, injury, pregnancy, lactation, etc.

\section{Malnutrition}

'Malnutrition' is a general term for a medical condition caused by an improper or insufficient diet [7]. The term usually refers to generally bad or faulty nutrition and is most often related to undernutrition. According to the World Health Organization (WHO), malnutrition is the 'cellular imbalance between supply of nutrients and energy and the body's demand for them to ensure growth, maintenance and specific functions', and is the greatest risk factor for illness and death worldwide. It can be associated with both undernutrition and overnutrition. Malnutrition and the state of deficiency or excess of energy, protein and other nutrients lead to measurable adverse effects on tissue, body function and appearance and clinical outcomes.

Anorexia, inadequate food intake or lack of food supplies and loss of appetite are probably the most common causes of malnutrition worldwide, especially in developing, but also in developed, countries. Anorexia can result from pathophysiological, psychological and general social problems. Different types of chronic and inflammatory diseases such as cystic fibrosis, chronic renal failure, stroke, Parkinson's disease, respiratory and orthopaedic problems, 
childhood malignancies, chronic inflammatory bowel diseases, fatigue, muscle weakness and difficulties with tasting, chewing and swallowing can lead to reduced food intake and malnutrition. Also, nausea and vomiting, which may result from certain diseases, and the use of certain drugs or specific treatments (chemotherapy, radiotherapy) may have a negative effect on appetite. Also, psychological factors such as anxiety and depression or the presence of dementia can cause malnutrition. Finally, malnutrition can have social causes, such as the institutionalisation of individuals (e.g. in hospitals, nursing homes), poverty and famine, poor food hygiene, inappropriate food supplies and the early cessation of breastfeeding.

\section{Health}

Nutrition education should be provided to a patient or family as determined by the organization's policy [8]. Some organizations may require a physician's order before nutrition education is provided, but once the determination is made for nutrition education, the dietitian or dietetic technician contacts the unit staff to assess the patient's schedule.

Nutrition education is based on a patient's lifestyle and current eating habits, as disclosed by a food history. Food intolerances also must be considered in developing diet patterns for patients. As stated earlier, because of shorter lengths of stay and the fact that news of patients' medical condition and prescribed lifestyle changes may require an adjustment period, inpatient instructions may be less effective. If possible, the patient should be scheduled for an outpatient return visit for the dietary instruction or clarification.

Nutrition education should be tailored to a patient's needs, education level, diagnosis, and lifestyle. For example, a diabetic patient who works a night shift should not be prescribed a meal pattern that accommodates the lifestyle of a day-shift worker.

Nutrition during the critical periods of fetal life and infancy determines brain development, while adult diseases such as high blood pressure and obesity are also thought to be linked to this early nutrition [9]. Therefore, nutrition, health and education policies should target mothers and their babies, school children and young women of childbearing age.

Various dietary recommendations designed to alleviate the problem of chronic degenerative diseases have been proposed by national organisations of developed countries and international organizations such as the WHO and the FAO. They recommend a decrease in the consumption of total fat, saturated fat, sugar and salt and an increase in the intake of fibre. It is hoped that the target can be reached by eating of more fruits, vegetables, cereals, pulses and nuts, and by eating of less refined sugar, cheese, and intensively produced meat and eggs. All these recommendations address the consumption side of the equation instead of tackling the root problem, which lies in food production and processing practices. But it is not a credible objective to implement these dietary recommendations when at the same time the agricultural and food industry is producing fat animals, removing fibre from cereals and incorporating refined fat and sugar in so many foods.

Moreover, it would be regrettable if, despite our extensive knowledge of the relationships between nutrition and health, developing countries were to import the mistakes of Western countries, at a time when attempts are being made to rectify them in the West. There is need for developing countries to acquire the considerable scientific and technical 'know how' that the Western food industry has to offer, but they should learn from our mistakes and not copy our agricultural and food policy indiscriminately.

The effects of the nutritional and health status of adults on labor productivity in developing countries are of utmost importance from a policy standpoint [10]. If, for example, adults are severely under-nourished and cannot earn an adequate living, then all household members, including children, will be at severe risk of malnutrition. Moreover, under-nourished adults have reduced immunity to infections and may not be able to perform strenuous tasks for long periods. Even for individuals in less strenuous occupations, nutrient deficiencies and poor environmental conditions, such as lack of sanitation, can increase sicknesses, there by leading to productivity loss. Thus, one would expect to see higher productivity among well-nourished populations, especially in developing countries, where there are often large variations in indicators of nutritional and health status such as anthropometric measures, dietary intakes and morbidity.

\section{Health claim}

Health claims are among the various types of claims allowed in food labeling [11]. They show a relationship between a nutrient or other substances in a food and a disease or health-related condition. They can be used on conventional foods or dietary supplements.

Health claims can include implied claims, which indirectly assert a diet-disease relationship. Implied claims may appear in brand names (such as "Heart Healthy"), symbols (such as a heartshaped logo), and vignettes when used with specific nutrient information. However, all labels bearing implied claims must also bear the full health claim (that is, the complete language required by the regulation).

Structure-function claims describe the role of an ingredient in affecting or maintaining the normal structure or function in humans; for example, "antioxidants maintain cell integrity." While health claims characterize the relationship between a substance and its ability to reduce the risk of a disease or health-related condition, structure-function claims describe the effect that a substance has on the normal structure or function of the body. The critical distinction here centers on normal versus disease. For example, "calcium builds strong bones" is a structure-function claim about normal bone development. Mention of osteoporosis or other disease (or even implying relationship to disease) would create a health claim. 
The line between structure-function claims and drug-health claim scan be extremely thin. For example, "supports the immune system" would be viewed as a structure - function claim-on the other hand, "supports your body's anti-viral capabilities" would be questioned as a veiled heath claim. Structure-function claims may not explicitly or implicitly link the relationship to a disease or health related condition.

\section{Diet}

Until very recently, most populations had no choice but to consume foods that were produced locally, and availability was often extremely seasonal [12]. This resulted in diets that were highly variable across the globe; for example, in some Arctic climates, almost no carbohydrates, fruits, or vegetables were consumed, and diets consisted mainly of fat and protein from animal sources. In other regions, populations subsisted on primarily vegetarian diets with the large majority of calories from carbohydrate sources. The fact that humans could survive and reproduce with such varied dietary patterns is a testimony to the adaptability of human biology.

In the last few decades, enormous changes have occurred in the diets of most populations. These changes were due to combination of increased wealth of some groups, new processing and preservation technologies, and greatly expanded transportation infrastructures. Collectively, these changes have allowed foods to be transported across and among continents and to be available virtually the whole year. At first, these changes globally were described as the "westernization" of diets because of increases in meat, dairy products, and processed foods. However, many of the more recent changes are not necessarily toward the diets of western countries, but instead emphasize refined starches, sugar and sugary beverages, and partially hydrogenated vegetable fats. These patterns, which have been described as "industrial diets", are usually the cheapest source of calories, and they have permeated poor populations of both rural and urban countries around the world.

The recent changes in diets, along with changes in physical activity and tobacco use, have profoundly affected rates of disease, sometimes positively but often adversely. On the positive side, we have seen dramatic declines in rates of coronary heart disease (CHD) in many western populations, where this has been the leading cause of death.

\section{Healthy diet}

Knowing what nutrients are and how much of each is recommended for optimal health is important [1]. However, this information is not always helpful in choosing a healthy diet. Because of the wide variety of foods available today, there are many combinations of foods that make up a healthy diet. Virtually any food can be part of a healthy diet as long as it is balanced with other food choices throughout the day or week to meet but not exceed dietary needs.
A healthy diet provides the right number of calories to keep your weight in the desirable range; the proper balance of carbohydrates, protein, and fat choices; plenty of water; and sufficient but not excessive amounts of essential vitamins and minerals. How this translates into specific food choices depends on individual needs and preferences, but in general, a healthy diet is rich in whole grains, fruits, and vegetables; contains the right types of fats; and is low in added sugars. Choosing this diet does not mean people need to give up their favorite foods. But it does require them to think about the variety and balance of foods.

Variety is important to a healthy diet because different foods provide different nutrients. Following the recommendations of MyPyramid can provide a healthy variety of foods and, hence, nutrients. Making a variety of choices from within each food group is as important as choosing the right amounts from each food group. For example, strawberries are a fruit that provides vitamin $C$ but little vitamin A, whereas apricots are a good a source of vitamin A, but provide less vitamin $C$. A diet that includes only strawberries will provide plenty of vitamin C, but may be lacking in vitamin A.

Balance is also part of a healthy diet. Balancing the diet means selecting foods that complement each other. This requires considering a food's nutrient density. Foods that are low in nutrient density, such as baked goods, snack foods, and sodas, should be balanced with nutrient-dense choices, such as salads, fruit, vegetables, and low-fat dairy products. A meal that consists of a burger, fries, and a soda, can be balanced by eating a salad, brown rice, and chicken at the next meal.

\section{My pyramid}

MyPyramid is a tool designed to help consumers choose foods that meet the recommendations of the Dietary Guidelines [1]. This food guide divides foods into five food groups (grains, vegetables, fruits, milk, and meat and beans) and oils, based on the nutrients that they provide. The five food groups and oils are represented by the colored triangles that make up the pyramid. The shape of the pyramid helps emphasize the recommendations for the amounts of food from each of the five food groups. Foods in the wider triangle columns of MyPyramid contain the most nutrients per calorie, which is referred to as nutrient density. Those in the narrow triangular columns have lower nutrient density. The figure climbing the pyramid is there to emphasize the importance of activity in maintaining nutritional health. Choosing the recommended amounts and varieties of foods from each group will provide a diet that meets nutrient recommendations and helps promote health, prevent disease, and support activity.

Almost everyone wants to eat for health and to prevent disease, but changing diet habits can be difficult [13]. To people who have eaten white bread all their lives, whole-wheat bread may taste 
strange at first. Fast foods are cheap, filling, and tasty. Sugar cravings are better satisfied with a candy bar than with an apple. Microwavable, pre-made, high-fat sandwiches are easier to prepare than a balanced dinner of baked chicken, sweet potato, and spinach. Many people just are not used to natural, healthy foods and often do not like them.

\section{Conclusion}

Nutrition is one of the needs of every human being on Earth, it is a process in which a person enters food into the body, while the continuation of the process in which food is processed into energy in the digestive tract is called digestion. When it comes to nutrition, it is essential to emphasize that sufficient amounts of all nutrients must be introduced into the body to keep the body healthy. The opposite is malnutrition, which weakens the human immune system.

\section{Bibliography}

1. Smolin LA and Grosvenor MB. "Basic Nutrition, Second Edition". Chelsea House, Infobase Publishing, New York, USA (2011): 9-10; 166-167; 24-26

2. Mudambi SR., et al. "Food Science, Revised Second Edition", New Age International (P) Ltd., Publishers, New Delhi, India (2006): 2 .

3. Wiseman G. "Nutrition and Health", Taylor and Francis, London, UK (2002): 1.

4. Wildman REC. "The Nutritionist - Food, Nutrition and Optimal Health, Second Edition", Routledge, Taylor and Francis, New York, USA (2009): 49.

5. Truswell S and Mann J. "Introduction" in Mann, J.; Truswell, A. S. (eds): "Essentials of Human Nutrition, Second Edition", Oxford University Press, Oxford, UK (2002): 1.

6. Dimosthenopoulos C., et al. "Principles of Healthy Nutrition" in Katsilambros, N.; Dimosthenopoulos, C.; Kontogianni, M.; Manglara, E.; Poulia, K. A. (eds): "Clinical Nutrition in Practice", Wiley-Blackwell, John Wiley and Sons Ltd, Chichester, UK (2002): 1-2.

7. Dimosthenopoulos C. "Malnutrition" in Katsilambros, N.; Dimosthenopoulos, C.; Kontogianni, M.; Manglara, E.; Poulia, K. A. (eds): „Clinical Nutrition in Practice“, Wiley-Blackwell, John Wiley and Sons Ltd, Chichester, UK (2010): 37-38.

8. Puckett RP. "Food Service Manual for Health Care Institutions, Third Edition", Jossey-Bass, Wiley, American Hospital Association, San Francisco, USA (2004): 269.

9. Bhargava A. "Food, Economics, and Health", Oxford University Press, Oxford, UK (2008):118.
10. Crawford M and Ghebremeskel K. "The equation between food production, nutrition and health" in Mepham, B. (ed): "Food Ethics", Routledge, London, UK (1996): 77-78.

11. Fortin ND. "Food Regulation - Law, Science, Policy, and Practice, Second Edition", John Wiley and Sons, Inc., Hoboken, USA (2017): 81-83.

12. Willett WC. "Public Health Benefits of Preventive Nutrition" in Bendich, A.; Deckelbaum, R. J. (eds): "Preventive Nutrition - The Comprehensive Guide for Health Professionals, Fourth Edition", Humana Press, Springer Science + Business Media, LLC, New York, USA (2010): 3-4.

13. Allman T. "Nutrition and Disease Prevention", Chelsea House, Infobase Publishing, New York, USA (2010): 143-144.

\section{Volume 3 Issue 12 December 2019} (C) All rights are reserved by Siniša Franjić. 